\title{
Less attention paid to waterborne SARS-CoV-2 spreading in Beijing urban communities
}

\author{
Chunyan Wang ${ }^{1}$, Jiangshan Wang ${ }^{1}$, Yi Liu $(\bowtie)^{1}$, Lei Zhang ${ }^{2}$, Yong Sun ${ }^{1}$, Jiuhui Qu ${ }^{1,3}$ \\ 1 School of Environment, Tsinghua University, Beijing 100084, China \\ 2 School of Environment, Renmin University of China, Beijing 100872, China \\ 3 Research Center for Eco-Environmental Sciences, Chinese Academy of Sciences, Beijing 100085, China
}

\section{H I G H L I G H T S}

-A survey on individual's perception of SARSCoV-2 transmission was conducted.

-Waterborne transmission risks are far less perceived by individuals.

- Precautions of preventing wastewater mediated transmission are implemented.

- The precautions for wastewater transmission are less favored by the public.

-Education level differs the most regarding to waterborne transmission perception.

\section{A R T I C LE IN F O}

Article history:

Received 1 November 2020

Revised 22 December 2020

Accepted 30 December 2020

Available online 15 February 2021

\section{Keywords:}

Environmental dissemination

Risk communication

Individual perception

\section{GRAPHIC A B S T R A C T}

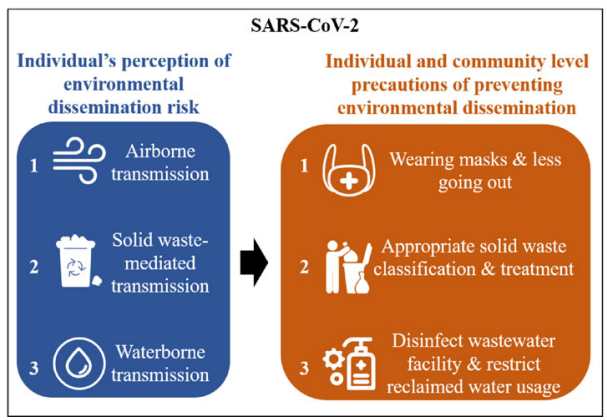

\section{A B S T R A C T}

SARS-CoV-2 has been detected in various environmental media. Community and individual-engaged precautions are recommended to stop or slow environmentally-mediated transmission. To better understand the individual's awareness of and precaution to environmental dissemination of SARS$\mathrm{CoV}-2$, an online survey was conducted in Beijing during March 14-25, 2020. It is found that the waterborne (especially wastewater mediated) spreading routes are far less perceived by urban communities. The precautions for wastewater transmission are less favored by the public than airborne and solid waste mediated spreading routes. Such risk communication asymmetry in waterborne transmission will be further enlarged in places with fragile water system. Furthermore, education level is the most significant attribution (Sig. $<0.05$ ) that causes the difference of awareness and precautions of the waterborne transmission among the respondents, according to the variance analysis results. Our survey results emphasize the urgent need for evidence-based, multifactorial precautions for current and future outbreaks of COVID-19.
The severe acute respiratory syndrome coronavirus 2 (SARS-CoV-2) has triggered the outbreak of pandemic of coronavirus disease 2019 (COVID-19) (declared by World Health Organization (WHO) on March 11th, 2020). It has caused over 60.3 million confirmed cases, 1.4 million confirmed deaths in 220 countries, areas or territories (as of November 27th, 2020) (WHO (2020) Coronavirus disease (COVID-19) pandemic). For case of New York City

$凶$ Corresponding author

E-mail: yi.liu@tsinghua.edu.cn
(USA), the COVID-19 has become as severe as or even worse than the most severe pandemic -1918 H1N1 influenza pandemic, in terms of the mortality (Faust et al., 2020). Community transmission is identified as one of the major types of COVID-19 transmission classifications identified by WHO, accounting for $47.8 \%$ of the reported countries, areas or territories (WHO (2020) Coronavirus Disease (COVID-19) Dashboard).

Controlling the environmental dissemination of SARS$\mathrm{CoV}-2$ is extremely necessary, as the SARS-CoV-2 was detected in air, water, wastewater, health care waste, 
sludge, and on surfaces (Liu et al., 2020; Lodder and de Roda Husman, 2020; Ong et al., 2020). These environmental media could result in potential airborne, waterborne, fomite transmissions (Meyerowitz et al., 2020). Thus, community and individual level precautions preventing environmentally-mediated infection are recommended.

Till now, little is known about to what extent local communities and individuals are aware and supportive of the above-mentioned environmental dissemination and precautions. Better awareness of the environmental dissemination and positive engagement of communities and individuals could lead to a higher level of risk perception and more effective and comprehensive precautions/responses (WHO (2020) Coronavirus disease (COVID-19) technical guidance: Risk communication and community engagement). To do so, risk communication and a sound understanding of individual's risk perception and responses are required. Aiming at raising the awareness of risk communication asymmetry about COVID-19, an online survey focusing on environmentally-mediated (airborne, waterborne, and fomite) transmission was distributed through social media (WeChat) to 3552 urban residents in Beijing, China from March 14 to 25, 2020. This survey contains: part A, 6 questions on individual's perception of community level environmental dissemination risk; part B, 9 questions on individual precautions; part C, 6 questions on individual's attitude toward community and public place management about COVID-19; and part D, 15 questions on personal and community information. The detailed information of this survey is provided in the Supporting Information (SI).

\section{Individuals are less aware of the waterborne transmission routes}

Based on the results of the survey (part A), it is found that waterborne transmission (W(1)-(4)) is the least perceived among all the three environmental dissemination-related precautions (c.f., Fig. 1). Among the four water-related transmission routes (W(1)-(4)), over 70\% of the respondents are worried about the community level wastewater mediated transmission routes (W(2)-(4)), while only $48 \%$ of the respondents are worried about public freshwater treatment (W(1)). Over $89 \%$ of the respondents concern the potential risk of aerosol transmission and solid waste management in their communities.

\section{Individuals take stricter precautions of preventing wastewater-mediated transmission routes}

The portions of respondents who take wastewater-related precautions (except for the precaution of avoiding using reclaimed water (in-home) (W8)) to the total respondents (i.e., 3552) are similar to the wastewater mediated transmission risk perception. Over $68 \%$ of the respondents indicate they would take precautions of preventing community/individual level wastewater mediated transmission (W(5)-7) (c.f., Fig. 1). Contrarily, fewer ( <78\%) respondents would sanitize the waste masks before littering, or disposal of the waste masks into a specific bin, comparing to individual's perception of solid waste transmission risk $(\sim 91 \%)$. This contrary might be explained by the "not in my backyard" theory, i.e., the surveyed wastewater-mediated transmission routes are taken places in home, where only the residents (respondents) are responsible, while the discarded solid waste are littered in the community, where the estates are responsible instead of the residents. As for the airborne transmission, the public is fully aware and is even taking extra precautions (e.g., A (8) enhanced house cleaning/disinfecting).

\section{Community-level wastewater mediated transmission preventions are less favored by individuals}

Regarding the community level precautions, over $72 \%$ of the respondents demonstrate their supportiveness of the community's stricter quarantine regulations and more appropriate solid waste management. Comparably, a lower portion $(<70 \%)$ of the respondents favor the community level wastewater mediated transmission preventions. Notably, around $67 \%$ of the respondents are supportive of keeping using reclaimed water for community recreational uses (W(11) (c.f., Fig. 1), which is higher than the portion of respondents who do not implement precaution $\mathrm{W} 8$ (i.e., 52\%). This finding indicates that respondents show stricter individual level precautions than community level precautions regarding to wastewatermediated transmissions.

The lower perception and weaker responses to the wastewater mediated transmission against the fact of the confirmed existence of viral RNA in wastewater (Lodder and de Roda Husman, 2020; Sun et al., 2020; Zhang et al., 2020). This finding emphasizes the risk communication asymmetry in pandemic risk management. Such less attention paid to wastewater-mediated transmission would pose an exposure risk to the public, especially to the people in less developed countries with poor water and sewage infrastructure (Usman et al., 2020). The fragile water system, such as lack of necessary infrastructure and supplements, will undoubtedly cause a higher risk of COVID-19 infection, even with better risk perception.

The possibility of wastewater-mediated transmission caused by the infected person through the defective wastewater plumbing system within the housing block (Gormley et al., 2020; Lodder and de Roda Husman, 2020) 




$\square$ Unknown $\square$ Not worried at all $\square$ Not too worried $\square$ Worried $\square$ Relatively worried $\square$ Very worried
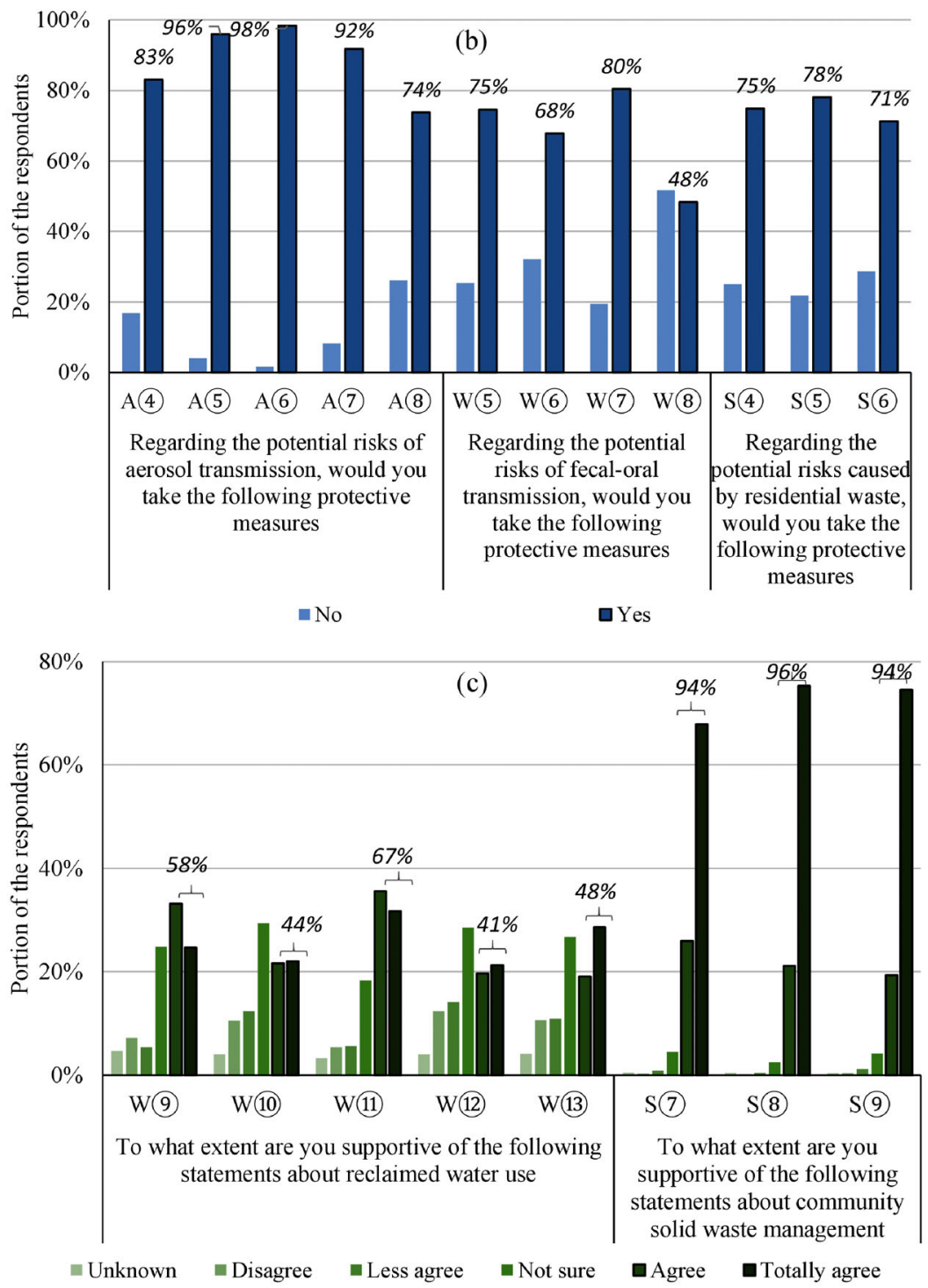

Fig. 1 Portion of respondents with different levels of awareness and precautions of SARS-CoV-2 environmental transmission. (a) Awareness of environmental transmission. (b) Precautions taken by individuals. (c) Supportiveness of community precautions

Notes: 1) The "worried", "relatively worried", and "very worried" responses are highlighted with black bolder in Fig. 1, and the sum of these responses are marked; 2) The "yes" responses, indicating that the respondents will take the mentioned precautions, are highlighted with black bolder and labeled in Fig. 1; 3) The "agree" and "totally agree" responses are highlighted with black bolder in Fig. 1, and the sum of these responses are marked; 4) The explanations of the attribution used in Fig. 1 are provided in Appendix 
should draw individuals' and communities' attention. A confirmed case evidenced the wastewater aerosol transmission during the SARS outbreak in 2003 in Hong Kong, China (Lee, 2003). Although there is no reported evidence, it is still possible that the wastewater mediated transmission has caused infection of COVID-19 in some places. Unfortunately, the current publicly recommended precautions fail to reduce the wastewater mediated transmission risks.

It is found that respondents' education level is the most significant attribution (Sig. $<0.05$ ), according to the results of the nonparametric tests analysis of the wastewater mediated transmission awareness and precautions grouped by individual's attributions (i.e., education level, gender, age, and job type) (c.f., Table 1). The mean comparison results indicate that individuals with higher education level are less worried about the wastewatermediated transmission, and more favorable for the stricter precautions than the individuals with lower education level. This may be explained that the well-educated individuals are better informed by the scientific findings, and till now, there is no evidence about the wastewatermediated transmission. However, as above mentioned, it is possible that wastewater-mediated transmission could happen. Those better-educated population would be more likely to be potentially exposed to a higher risk of COVD19 infection via wastewater mediated transmission. Moreover, the individuals, who are medical-related staff, tend to be less worried about the wastewater-mediated transmission, which might because they are exposed to higher risks of aerosol transmission.

Such a severe sanitation situation calls for in-time and appropriate responses to maintain and enhance the water system to protect potentially vulnerable populations who live with fragile water system or with higher education level. Urban communities, local partners, and other stakeholders should fulfill the knowledge gaps and recommend pandemic precautions through evidencebased, multifactorial approaches.

In summary, the online survey conducted during the pandemic shows that significant risk communication asymmetry still exists in various environmentallymediated transmission routes, especially the wastewater mediated transmission routes. Better risk perception of environmental dissemination is emerging needed to prepare for current and future outbreaks of COVID-19 pandemic.

Table 1 The statistical analysis of awareness and precautions of SARS-CoV-2 waterborne transmission and individual's attributions

\begin{tabular}{|c|c|c|c|c|c|c|c|c|c|}
\hline \multirow[b]{3}{*}{ Questions } & \multirow[b]{3}{*}{ No. } & \multicolumn{4}{|c|}{ Nonparametric tests analysis ${ }^{1}$} & \multicolumn{4}{|c|}{ Mean comparison analysis ${ }^{2}$} \\
\hline & & \multirow[b]{2}{*}{$\begin{array}{l}\text { Education } \\
\text { level }^{3,4}\end{array}$} & \multirow[b]{2}{*}{ Gender ${ }^{3,5}$} & \multirow[b]{2}{*}{$\operatorname{Age}^{6}$} & \multirow[b]{2}{*}{ Job type $\mathrm{e}^{3,7}$} & \multicolumn{2}{|c|}{ Education level } & \multicolumn{2}{|c|}{ Job type } \\
\hline & & & & & & $\begin{array}{l}\text { High school } \\
\text { (or equivalent) } \\
\text { or below }\end{array}$ & $\begin{array}{c}\text { College } \\
\text { (or equivalent) } \\
\text { or above }\end{array}$ & $\begin{array}{l}\text { Non-medical } \\
\text { related work }\end{array}$ & $\begin{array}{c}\text { Medical related } \\
\text { work }\end{array}$ \\
\hline \multirow{4}{*}{$\begin{array}{l}\text { Are you worried about } \\
\text { the SARS-CoV-2 trans- } \\
\text { mission via the water/ } \\
\text { wastewater system? }^{8}\end{array}$} & W(1) & 0.000 & 0.299 & 0.000 & 0.002 & 3.88 & 3.68 & 3.73 & 3.34 \\
\hline & W(2) & 0.000 & 0.249 & 0.223 & 0.000 & 4.46 & 4.29 & 4.34 & 3.86 \\
\hline & W(3) & 0.000 & 0.463 & 0.048 & 0.000 & 4.67 & 4.40 & 4.47 & 3.96 \\
\hline & $\mathrm{W}(4)$ & 0.000 & 0.519 & 0.168 & 0.005 & 4.36 & 4.16 & 4.21 & 3.90 \\
\hline \multirow{5}{*}{$\begin{array}{l}\text { To what extent are you } \\
\text { supportive of the fol- } \\
\text { lowing statement about } \\
\text { recycled water use }\end{array}$} & W(9) & 0.000 & 0.992 & 0.131 & 0.271 & 4.59 & 4.46 & - & - \\
\hline & $\mathrm{W}(10$ & 0.000 & 0.432 & 0.301 & 0.637 & 4.39 & 4.16 & - & - \\
\hline & W(11) & 0.000 & 0.958 & 0.000 & 0.482 & 4.82 & 4.70 & - & - \\
\hline & $\mathrm{W}(12)$ & 0.000 & 0.600 & 0.000 & 0.802 & 4.82 & 4.63 & - & - \\
\hline & W(13) & 0.000 & 0.497 & 0.570 & 0.893 & 5.57 & 4.26 & - & - \\
\hline
\end{tabular}

Notes:

1) This sub-table lists the significance results of nonparametric tests analysis;

2) This sub-table lists the mean selections for W(1)-W(4) grouped by education level and job type, and W(9)-W(13) grouped by education level, which are the only three

clusters with significance $<0.05$ for all the awareness and/or precautions of SARS-CoV-2 waterborne transmission;

3) The Kruskal-Wallis test is used for comparing only 2 groups;

4) The classification for education is re-grouped as 1-high school (or equivalent) or below and 2-college (or equivalent) or above;

5) The classification for gender is 1-male and 2-female;

6) The Kruskal-Wallis test is used for comparing more than 2 independent samples;

7) The classification for job type is re- grouped as 1-non-medical related work and 2-medical related work;

8) The selections for W(1)-W(4) are converted into numeric selections: 1 refers to "unknown", 2 refers to "not worried as all", 3 refers to "not too worried", 4 refers to

"worried", 5 refers to "relatively worried", and 6 refers to "very worried";

9) The selections for W(9)-W(13) are converted into numeric selections 1 refers to "unknown", 2 refers to "disagree", 3 refers to "less agree", 4 refers to "not sure", 5 refers to "agree", and 6 refers to "totally agree" 
Acknowledgements The authors thank Prof. Xia Huang for valuable suggestions during the manuscript preparation. This research is funded by Chinese Academy of Engineering (Mechanism of the Spread of the Covid-19 in Environments and Cross-media Risk Control, 2020-ZD-15).

Electronic Supplementary Material Supplementary material is available in the online version of this article at https://doi.org/10.1007/s11783-021$1398-2$ and is accessible for authorized users.

\section{Appendix}

The explanations of the abbreviations used in Fig. 1 and Table 1:

Are you worried about the SARS-CoV-2 transmission via the aerosol transmission?

A(1) Go the supermarket without wearing masks

A(2) Take the bus without wearing masks

A(3) Exercise in public places without wearing masks

Are you worried about the SARS-CoV-2 transmission via the water/

wastewater system?

W(1) Freshwater may be contaminated

W(2) Wastewater plumbing system within the housing block

W(3) Community septic tank and the drainage pipeline

W(4) Reclaimed water used within the residential buildings

Are you worried about the SARS-CoV-2 transmission via the solid waste

management in your community?

S(1) Not timely cleared and transported in community

S(2) Improper treatment of solid waste in community

S(3) Improper disposal of discarded masks in community

Regarding the potential risks of aerosol transmission, would you take the following protective?

A(4) Not take public transportation

A(5) Minimize the time and frequency of going out

A(6) Wear a mask when going out

A(7) Increase the frequency of room ventilation

A8 Disinfect regularly at home

Regarding the potential risks of fecal-oral transmission, would you take the following protective measures?

W(5) Check and keep the sewer water seal intact

W6 Regularly disinfect the water seal of the sewer at home

W(7) Close the toilet lid when flushing

W8 Avoid using reclaimed water (in-home)

Regarding the potential risks caused by solid waste, would you take the following protective measures?

S(4) Properly dispose used masks (such as disinfection, folding before discard)

S(5) Discard used masks to specific place

S(6) Classify waste as required

To what extent are you supportive of the following stating about recycled water use?

W(9) The reclaimed water could still be used for toilet

W(10) The reclaimed water used in residential buildings should be replaced by freshwater

W(11) The reclaimed water could still be used for recreation

W(12) The reclaimed water use for recreation should be replaced by freshwater

W(13) The reclaimed water should be completed forbidden during the

pandemic

To what extent are you supportive of the following stating about community solid waste management?

S 7 The solid waste should be cleared more frequently

S 8 The solid waste should be sanitized everyday

S(9) The waste masks should be disposal and treated separately

\section{References}

Faust J S, Lin Z, Del Rio C (2020). Comparison of estimated excess deaths in New York City during the COVID-19 and 1918 influenza pandemics. JAMA Network Open, 3(8): e2017527

Gormley M, Aspray T J, Kelly D A (2020). COVID-19: Mitigating transmission via wastewater plumbing systems. Lancet. Global Health, 8(5): e643

Lee S H (2003). The SARS epidemic in Hong Kong (China): What lessons have we learned? Journal of the Royal Society of Medicine, 96(8): 374-378

Liu Y, Ning Z, Chen Y, Guo M, Liu Y, Gali N K, Sun L, Duan Y, Cai J, Westerdahl D, Liu X, Xu K, Ho K, Kan H, Fu Q, Lan K (2020). Aerodynamic analysis of SARS-CoV-2 in two Wuhan hospitals. Nature, 582(7813): 557-560

Lodder W, de Roda Husman A M (2020). SARS-CoV-2 in wastewater: Potential health risk, but also data source. Lancet. Gastroenterology \& Hepatology, 5(6): 533-534

Meyerowitz E A, Richterman A, Gandhi R T, Sax P E (2020). Transmission of SARS-CoV-2: A review of viral, host, and environmental factors. Annals of Internal Medicine, M20-M5008

Ong S W X, Tan Y K, Chia P Y, Lee T H, Ng O T, Wong M S Y, Marimuthu K (2020). Air, surface environmental, and personal protective equipment contamination by severe acute respiratory syndrome coronavirus 2 (SARS-CoV-2) from a symptomatic patient. Journal of the American Medical Association, 323(16): 1610-1612

Sun J, Zhu A, Li H, Zheng K, Zhuang Z, Chen Z, Shi Y, Zhang Z, Chen S, Liu X, Dai J, Li X, Huang S, Huang X, Luo L, Wen L, Zhuo J, Li Y, Wang Y, Zhang L, Zhang Y, Li F, Feng L, Chen X, Zhong N, Yang Z, Huang J, Zhao J, Li Y (2020). Isolation of infectious SARSCoV-2 from urine of a COVID-19 patient. Emerging Microbes \& Infections, 9(1): 991-993

Usman M, Farooq M, Hanna K (2020). Existence of SARS-CoV-2 in wastewater: Implications for its environmental transmission in developing communities. Environmental Science \& Technology, 54 (13): 7758-7759

Zhang D, Ling H, Huang Z, Li J, Li W, Yi C, Zhang T, Jiang Y, He Y, Deng S, Zhang X, Wang X, Liu Y, Li G, Qu J (2020). Potential spreading risks and disinfection challenges of medical wastewater by the presence of severe acute respiratory syndrome coronavirus 2 (SARS-CoV-2) viral RNA in septic tanks of Fangcang Hospital. Science of the Total Environment, 741: 140445 